\section{DIÁLOGOS SOBRE O ENSINO DOS ESPORTES: FORMAÇÃO CONTINUADA POR MEIO DA PESQUISA-AÇÃO}

\author{
DIALOGUES ON SPORTS TEACHING: CONTINUOUS EDUCATION THROUGH \\ ACTION RESEARCH
}
DIÁLOGO SOBRE LA ENSEÑANZA DE DEPORTES: FORMACIÓN CONTINUA MEDIANTE INVESTIGACIÓN-ACCIÓN

\begin{abstract}
Robson Machado Borges*, Fernando Jaime González*, Adroaldo Cezar Araujo Gaya**, Larissa Rafaela Galattit**
\end{abstract}

\begin{abstract}
Palavras chave:
Esportes.

Professores.

Ensino.

Educação

continuada.

Resumo: Esta pesquisa buscou verificar quais as decorrências de uma experiência de formação colaborativa, nas concepções e nas formas de professores de Educação Física ensinarem jogos esportivos coletivos. Por meio de uma pesquisa-ação com cinco docentes, foram realizados 26 encontros de estudos, sendo 21 teóricos e cinco práticos. Os resultados apontam que é possível uma mudança nas concepções e nas formas de os professores de Educação Física ensinarem os jogos esportivos coletivos. Os educadores que atuam sob a ótica do modelo tradicional, pautado na execução e na repetição de gestos motores, podem mudar sua capacidade de compreender o fenômeno esportivo. Todavia, o empreendimento é longo, trabalhoso e precisa estar bem ancorado em fundamentos teóricos relacionados à dimensão tática, aliando o estudo teórico ao estudo prático e sendo conduzido por pesquisadores com expertise em relação ao tema.
\end{abstract}

Keywords:

Sports.

Teachers.

Teaching.

Education

continuing

Palabras clave:

Deportes.

Maestros.

Enseñanza.

Educación continua

\begin{abstract}
This research focused on the consequences of a collaborative training experience in the conceptions and ways Physical Education teachers teach collective sports games. Action research was conducted with five teachers and included 26 study meetings of which 21 were theoretical and five were practical. The results show that it is possible to change the conceptions and the ways Physical Education teachers teach collective sports games. Educators working under the traditional model based on execution and repetition of motor gestures can change their understanding of the sports phenomenon. However, the project is long and hard, and it needs to be well grounded on theoretical foundations related to the tactical dimension, combining theoretical and practical study and being conducted by researchers with expertise on the topic.
\end{abstract}

Resumen: Esta investigación buscó verificar cuales son las consecuencias de una experiencia de formación colaborativa en las concepciones y en las formas de enseñar juegos de deportes colectivos de profesores de Educación Física. A través de una investigación-acción con cinco maestros, fueron realizados 26 encuentros de estudios - 21 teóricos y 5 prácticos. Los resultados muestran que es posible un cambio en las concepciones y en las formas de los profesores de Educación Física enseñaren juegos de deportes colectivos. Los educadores que actúan según el modelo tradicional, basado en la ejecución y en la repetición de gestos motores, pueden cambiar su capacidad de comprender el fenómeno deportivo. Pero el emprendimiento es largo, exige mucho trabajo y debe estar "bien anclado" en fundamentos teóricos relacionados a la dimensión táctica, el estudio teórico debe estar aliado al estudio práctico, y debe ser conducido por investigadores con expertise en relación al tema.
*Universidade Regional do Noroeste do Estado. UNIJUÍ. ljuí, RS, Brasil. E-mail: robsonmachadoborges@gmail. com; fjg@ @uijui.edu.br

** Universidade Federal do Rio Grande do Sul. UFRGS. Porto Alegre, RS, Brasil. E-mail: acgaya @esef.ufgrs.br

${ }^{* *}$ Universidade Estadual de Campinas. UNICAMP. Limeira, SP, Brasil. E-mail: lagalatti@hotmail.com

Recebido em: 08-03-2017 Aprovado em: 05-06-2017

(c) (1) (8) Licence 


\section{INTRODUÇÃO}

O esporte é uma das manifestações culturais mais ensinadas para crianças e jovens na contemporaneidade. Diversos são os espaços e os formatos que propiciam a aprendizagem dessa prática, particularmente, os denominados Jogos Esportivos Coletivos (JEC). Entretanto, autores de diversos países (BAYER, 1994; CÔTÉ; HANCOCK, 2014; GARGANTA, 2013; GRIFFIN; MITCHELL; OSLIN, 1997; KIRK; MACPHAIL, 2002; LIGHT; TAN, 2006; MESQUITA; GRAÇA, 2013; PEARSON; WEBB, 2008; SIEDENTOP, 2002; TAVARES, 2013) apontam que a forma como os esportes têm sido convencionalmente ensinados dificulta uma aprendizagem que direcione os alunos a uma apropriação efetiva do conhecimento necessário para sua prática.

Essa situação, em grande medida, é produto da forma de ensino não ser adequada às características dos JEC. Ainda se enfatiza, quase que exclusivamente, a transmissão de habilidades técnicas próprias da modalidade, desconsiderando a dimensão tática ou a tomada de decisão implicada nos JEC (CARMEL; AGARWAL, 2001; KIRK; MACPHAIL, 2002; PEARSON; WEBB, 2008). Nessa abordagem tradicional a "[...] técnica é aplicada de forma isolada e descontextualizada [...] com pouca relevância para as exigências do jogo" (MESQUITA, 2013, p. 103). No mesmo sentido, Graça (2013) aponta que é um engano supor que 0 ensino dos JEC se limita à instrução de habilidades isoladas. $O$ autor afirma que

\section{[...] aquilo que parece ser uma autoevidência, isto é, se não ensinarmos previamente as habilidades do jogo, os alunos não serão capazes de jogar, tem sido a maior falácia das didáticas do ensino dos jogos, porque o tempo gasto a aprender habilidades isoladas nunca ou muito pouco se converte em ganhos para o jogo. A transferência das aprendizagens para o jogo pura e simplesmente não acontece (GRAÇA, 2013, p. 89-90).}

Dessa maneira, a forma como ainda hoje se ensinam os JEC dificulta que o aluno se aproprie dos conhecimentos necessários para poder atuar de modo proficiente 1 . Em muitos cursos de Educação Física (EF), nas instituições de ensino superior no Brasil, o ensino dos esportes tem sido pautado - em sua maioria - em um modelo tradicional, centrado na execução e na reprodução de movimentos ${ }^{2}$ (COUTINHO; SILVA, 2009). Logo, "[...] o ensino dos esportes não vem sendo desenvolvido a contento na formação profissional com consequências negativas na educação básica" (COUTINHO; SILVA, 2009, p. 130). Estudos mostram que as vivências pré-universitárias e a própria formação acadêmica colaboram para a manutenção dessas práticas (COUTINHO; SILVA, 2009; RAMOS; GRAÇA; NASCIMENTO, 2006). Esse fato preocupa, porque atuar de forma proficiente em um jogo esportivo é condição importante para poder usufruir das oportunidades de lazer e ampliação das redes de sociabilidade proporcionadas por esse universo.

Partindo da inquietação gerada pelo encadeamento das ideias apresentadas, uma área importante de estudo é a identificação dos conceitos e procedimentos que orientam os professores de EF no ensino dos esportes. Parece relevante pesquisar tanto os sentidos e significados que os docentes atribuem à forma que trabalham, quanto buscar alternativas para

1 Segundo González e Fraga (2009, p. 178), "[...] este conceito é sinônimo de: competente, capaz, hábil. Ser proficiente numa prática corporal significa poder dar conta das exigências colocadas quando de sua realização no contexto do lazer. Trata-se de um grau de domínio da prática que permite ao sujeito 'se virar' quando a realiza".

2 Entendemos que pela característica dos JEC, com base na lógica interna (GONZÁLEZ; BRACHT, 2012), a dimensão tática precisa receber grande atenção dos professores no processo de ensino, em vez de focar apenas em técnicas isoladas. 
contribuir com a mudança de concepção tradicional - centrada na execução e na reprodução de movimentos - de ensino dos JEC. A partir dessa compreensão, torna-se necessário buscar alternativas para contribuir com mudanças na concepção dos professores, a respeito do ensino dos esportes.

Nesse processo de busca de transformação na compreensão dos educadores, uma perspectiva que tem sido apontada como consistente e eficaz, na formação continuada, é a pesquisa-ação. Tripp (2005) defende que a pesquisa-ação é uma estratégia para 0 aperfeiçoamento de professores, buscando o aprimoramento do ensino, em prol do aprendizado dos alunos. No mesmo sentido, Franco (2005, p. 500) afirma que a pesquisa-ação consiste em "[...] produzir transformações de sentido, ressignificações, ao que fazemos ou pensamos".

Nesse viés, faz-se indispensável estudar com os docentes, propiciando-lhes a reflexão e o contato com temas imprescindíveis para a realização de um ensino que permita aos alunos a apropriação plena dos JEC. Nesse movimento, parece ser fundamental compreender quais ações em uma formação continuada propiciam a mudança, assim como quais elementos a dificultam, no intuito de construir conhecimentos sobre a continuação dos estudos nesse campo.

Partindo dessa contextualização inicial, este estudo teve como objetivo geral verificar os desdobramentos, entraves e possibilidades de uma experiência de formação colaborativa, nas concepções e nas formas de professores de EF ensinar JEC. Especificamente, buscou-se: a) compreender os conceitos e sentidos que orientavam docentes de EF no processo de ensino dos esportes; b) descrever como as possibilidades de diagnóstico de um jogo com interação entre adversários são condicionadas pela compreensão da lógica interna das práticas motoras; c) verificar a possível ocorrência de mudança nas concepções dos professores, ao longo da experiência de formação, em relação aos processos de ensino dos JEC.

\section{PROCEDIMENTOS METODOLÓGICOS}

A investigação foi pautada em uma abordagem qualitativa, com foco na interpretação dos sentidos e significados do trabalho docente. Mais especificamente, caracteriza-se como uma pesquisa-ação, processo investigativo no qual os participantes compartilham as decisões implicadas em seu desdobramento. De acordo com Thiollent (2011), trata-se de um tipo de investigação social que busca resolver uma dificuldade coletiva, de modo que pesquisadores e sujeitos se envolvam de forma cooperativa. No entendimento de Greenwood e Levin (2006), na busca por uma mudança social útil, os estudos sociais precisam assumir a pesquisa-ação quando se deseja alcançar resultados válidos.

Os sujeitos participantes da investigação foram cinco professores, quatro homens e uma mulher, com formação em EF, que atuavam no ensino de JEC para crianças e jovens nas regiões Centro-Leste e Metropolitana de Porto Alegre no Rio Grande do Sul. O grupo de docentes partícipes se caracteriza pela heterogeneidade quanto à idade (de 27 a 45 anos), à instituição na que realizaram a formação inicial (três universidades diferentes), ao período de conclusão da graduação (de 2005 a 2009), ao tempo de experiência docente (de 5 a 15 anos), à formação (graduação a mestrado) e à relação com o esporte (jogador amador de basquetebol, proprietário de uma escolinha de futsal, jogador de voleibol profissional, treinador de equipe de futsal e vivência em jogos escolares). Esses participantes, juntamente com um dos pesquisadores, formaram um grupo de estudos (GE). 
Os instrumentos utilizados para a produção dos dados da pesquisa foram: a) as filmagens das aulas dos professores com seus alunos, ministradas antes e após a investigação; b) as gravações das falas dos sujeitos durante as reuniões de estudo; c) as filmagens dos encontros do GE; d) as anotações realizadas pelos docentes - incluindo planejamento de aulas, proposições de tarefas e intervenções dos professores -, as quais foram recolhidas ao final das reuniões; e) os registros, em um diário de campo, sobre as falas, manifestações, depoimentos e comportamentos dos professores, tanto durante os encontros do grupo quanto nas aulas práticas com seus alunos. Cabe ressaltar que, anteriormente aos encontros, entrevistas foram realizadas com os participantes buscando conhecer a trajetória de cada um, vinculada ao esporte.

O processo de investigação teve como base empírica 26 encontros do GE (21 teóricos e cinco práticos, cada um com duração média de 1h30min, realizados no local em que os professores trabalham, em horário de trabalho), dez observações/filmagens das aulas práticas - com duração de uma hora cada - e duas participações em que um dos pesquisadores ministrou aulas juntamente com os professores nas suas turmas, totalizando, assim, 38 idas a campo.

Nos encontros de estudos, o pesquisador integrante do grupo atuou como mediador de diálogos crítico-reflexivos, de modo que o conjunto de professores pôde expressar suas ideias e convicções sobre o ensino dos JEC. Durante os encontros o grupo se ocupou com diversos assuntos considerados essenciais, no marco desta pesquisa, para ensinar os JEC e outros temas que os docentes propuseram.

Assim, com frequência de uma vez por semana, os encontros assumiram o formato de reuniões e seminários. Nesse processo, buscou-se a construção de conhecimento por meio de um processo coletivo, levando em consideração os saberes dos professores - pressuposto da pesquisa-ação. No Quadro 1 consta a relação dos temas abordados nos encontros. Esses assuntos foram propostos com base na proposta de González e Bracht (2012).

Quadro 1 - Temas abordados nos encontros do grupo de estudos

\begin{tabular}{|c|c|c|}
\hline Encontro & Revisão antes do tema central & Tema central do dia \\
\hline $1^{0}$ & & - Apresentação da proposta de estudos \\
\hline $2^{0}$ & & $\begin{array}{l}\text { - Realização do } 1^{0} \text { diagnóstico, } 1^{0} \text { plano de aula e } 1^{\text {a }} \text { proposição } \\
\text { de tarefas para o ensino de conteúdos específicos }\end{array}$ \\
\hline $3^{0}$ & & - Elementos do desempenho esportivo (tática e técnica) \\
\hline $4^{0}$ & $\begin{array}{l}\text { - Elementos do desempenho } \\
\text { esportivo (tática e técnica) }\end{array}$ & $\begin{array}{l}\text { - Elementos do desempenho esportivo (estratégia, sistema de } \\
\text { jogo, capacidade física, capacidade volitiva) }\end{array}$ \\
\hline $5^{0}$ & $\begin{array}{l}\text { - Elementos do desempenho } \\
\text { esportivo (estratégia, sistema } \\
\text { de jogo, capacidade física, } \\
\text { capacidade volitiva) }\end{array}$ & $\begin{array}{l}\text { - Lógica interna dos esportes } \\
\text { - Mecanismos de processamento da informação }\end{array}$ \\
\hline $6^{0}$ & $\begin{array}{l}\text { - Mecanismos de } \\
\text { processamento da informação }\end{array}$ & $\begin{array}{l}\text { - Subpapéis dos esportes de invasão } \\
\text { - Habilidades motoras }\end{array}$ \\
\hline $7^{0}$ & $\begin{array}{l}\text { - Subpapéis dos esportes de } \\
\text { invasão } \\
\text { - Habilidades motoras }\end{array}$ & $\begin{array}{l}\text { - Modelos de ensino } \\
\text { - Diagnóstico }\end{array}$ \\
\hline $8^{0}$ & - Modelos de ensino & - Diagnóstico \\
\hline 90 & & $\begin{array}{l}\text { - Diagnóstico } \\
\text { - Tipos de tarefas }\end{array}$ \\
\hline
\end{tabular}


Continuação do quadro 1 ...

\begin{tabular}{|c|c|c|}
\hline $10^{\circ}$ & - Tipos de tarefas & $\begin{array}{l}\text { - Intervenção do professor } \\
\text { - Papel do aluno }\end{array}$ \\
\hline $11^{0}$ & $\begin{array}{l}\text { - Intervenção do professor } \\
\text { - Papel do aluno }\end{array}$ & - Métodos de ensino \\
\hline $12^{0}$ & & - Seminário métodos de ensino \\
\hline $13^{0}$ & & - Seminário métodos de ensino \\
\hline $14^{0}$ & - Métodos de ensino & - Diagnóstico \\
\hline $15^{0}$ & & - Seminário unidade didática \\
\hline $16^{0}$ & & - Seminário unidade didática \\
\hline $17^{0}$ & & - Revisão de todos os assuntos \\
\hline $18^{\circ}$ & & - Revisão de todos os assuntos \\
\hline $19^{\circ}$ & & $\begin{array}{l}\text { - Revisão de todos os assuntos } \\
\text { - Criação de um método de ensino } \\
\text { - Planejamento de duas aulas }\end{array}$ \\
\hline $20^{\circ}$ & & $\begin{array}{l}\text { - Encontro prático em que o pesquisador ministrou uma aula } \\
\text { para ensinar a desmarcar-se para receber a bola }\end{array}$ \\
\hline $21^{\circ}$ & & $\begin{array}{l}\text { - Encontro prático em que o pesquisador ministrou uma aula } \\
\text { para ensinar a posicionar-se em uma linha imaginária entre o } \\
\text { atacante e a meta }\end{array}$ \\
\hline $22^{\circ}$ & & $\begin{array}{l}\text { Encontro prático: } \\
\text { - O professor } 1 \text { ministrou uma aula com o objetivo de passar ao } \\
\text { companheiro em melhores condições } \\
\text { - O professor } 2 \text { ministrou uma aula com o objetivo de procurar } \\
\text { jogar com os companheiros }\end{array}$ \\
\hline $23^{\circ}$ & & $\begin{array}{l}\text { Encontro prático: } \\
\text { - O professor } 4 \text { ministrou uma aula com o objetivo de observar } \\
\text { antes de agir } \\
\text { - O professor } 3 \text { ministrou uma aula com o objetivo de } \\
\text { desmarcar-se para receber a bola }\end{array}$ \\
\hline $24^{\circ}$ & & $\begin{array}{l}\text { Encontro prático: } \\
\text { - O professor } 5 \text { ministrou uma aula com o objetivo de finalizar } \\
\text { no momento adequado }\end{array}$ \\
\hline $25^{\circ}$ & & - Avaliação do desempenho do aluno \\
\hline $26^{\circ}$ & & $\begin{array}{l}\text { - Realização do } 2^{0} \text { diagnóstico e } 2^{2} \text { proposição de tarefas } \\
\text { - Encerramento }\end{array}$ \\
\hline
\end{tabular}

Fonte: os autores

No que se refere aos cuidados éticos, este estudo obedeceu aos procedimentos estabelecidos para a pesquisa científica e foi aprovado pelo Comitê de Ética em Pesquisa da Universidade Federal do Rio Grande do Sul, sob parecer de número 535.88. Cabe ressaltar que os professores participantes desta investigação tiveram acesso à leitura da pesquisa e concordaram com todas as falas e informações referidas a eles. No mesmo sentido, visando à preservação da identidade dos participantes, os nomes dos docentes foram substituídos por algarismos arábicos.

\section{ANÁLISE E DISCUSSÃO DOS RESULTADOS}

Os achados desta investigação são apresentados em duas perspectivas. Na primeira, se descrevem os entraves e as possibilidades existentes neste tipo de estudo. Na segunda, se discutem 
as mudanças na concepção de ensino dos professores participantes da pesquisa, a respeito do ensino dos JEC.

Na primeira perspectiva, a investigação permitiu identificar que algumas concepções internalizadas pelos professores se constituem em verdadeiros entraves para mudar a forma de compreender e desenvolver 0 ensino dos JEC. Em linhas gerais, essas concepções passam pelo entendimento de que: a) o desempenho do aluno em um jogo esportivo depende de uma capacidade inata/natural - as pessoas nascem para -, tirando ou limitando a possibilidade de 0 professor afetar essa condição; b) 0 aprendizado dos alunos depende, fundamentalmente, além da capacidade natural, do (des)interesse dos próprios sujeitos; c) o pleno domínio da execução dos movimentos (fundamentos) é imprescindível para uma atuação eficaz em JEC, uma vez que o esporte se explica como uma soma de habilidades motoras ou a simples "aplicação" destas no jogo.

Ao observar o processo de pesquisa-ação é possível constatar que a mudança de concepção em relação ao ensino dos JEC se concretizou a partir do final do décimo sétimo encontro, quando iniciou a revisão de todos os assuntos abordados até esse momento ${ }^{3}$. Interpreta-se que a articulação conceitual dos diferentes temas estudados permitiu que uma nova forma de compreender o ensino dos esportes fizesse sentido para os professores. Eis algumas falas dos docentes que indicam essa alteração: "Minhas aulas eram totalmente da metodologia antiga" (Prof. 3); "Eu aprendi muito. Algo novo, que se bem trabalhado os alunos vão gostar e aprender muito mais dessa maneira. [...] eu acho que mudou completamente minha visão de ver as coisas" (Prof. 1).

No entanto, a mudança de concepção de ensino obtida ao final do décimo sétimo encontro não foi suficiente para que os professores mudassem de modo substancial sua forma de proceder nas aulas. Eles passaram a utilizar mais as tarefas que possibilitam o desenvolvimento da tomada de decisão, oferecendo aos alunos um papel mais ativo nas aulas, mas não conseguiam mobilizar os outros assuntos estudados nos encontros. Faltava, na perspectiva dos professores, "a parte prática", a experimentação corporal que lhes permitisse vivenciar os conteúdos a serem ensinados.

Com isso, a pesquisa, nessa etapa, permitiu constatar que os estudos teóricos não foram suficientes para que os professores pudessem mudar a intervenção. Eles compreendiam que era necessário fazer diferente, mas não conseguiam ministrar aulas a partir dessa nova concepção. Mesmo havendo demonstrações corporais durante os encontros teóricos, em uma sala de aula, ficou constatado que os professores precisaram ver, sentir, experimentar, ser questionados, orientados e testar as novas compreensões em situações de jogo, alternando o papel de professor e aluno, para conseguirem ensaiar novas formas de ensino.

Interpreta-se que a constituição dos novos saberes foi produto da combinação do estudo e debate sobre os temas tratados no grupo, do processo de reflexão crítica sobre a elaboração de propostas de ensino - em vez de apenas se apropriar das existentes -, das explicações/ argumentações e das demonstrações corporais realizadas de forma insistente durante os encontros e as vivências práticas.

Finalmente, para verificar mudanças na concepção dos docentes acerca do ensino dos JEC, realizaram-se, na perspectiva descrita por Tripp (2005), análises comparativas, antes e após os estudos: a) dos diagnósticos de um jogo reduzido (3v3); b) dos planejamentos das aulas; c) das filmagens das atuações dos professores com os seus discentes.

3 Temas estudados estão descritos no Quadro 1. 
Tomando como base a comparação dos diagnósticos realizados pelos professores (antes e depois) sobre as dificuldades dos alunos num jogo reduzido, é possível afirmar que tanto as concepções de ensino como as do processo de regulação interna da atuação dos jogadores condicionam a leitura que os docentes são capazes de fazer sobre as dificuldades dos jogadores e, consequentemente, afetam as decisões sobre o que ensinar. Dito de outra forma, os professores ao operarem com a concepção de esporte que explica o desempenho no jogo como produto exclusivo do domínio das habilidades motoras, no diagnóstico conseguem identificar somente problemas de execução técnica. Logo, o ensino, condizente com o que conseguiam observar, era orientado para resolver os problemas dos "fundamentos", quando efetivamente a maioria das dificuldades dos jogadores tinha origem na tática individual - assunto que os alunos necessitavam prioritariamente aprender -, o que demandaria o ensino de outros conteúdos.

A comparação dos diagnósticos foi realizada com base em uma análise de conteúdo. Metodologicamente, buscou-se identificar os núcleos de sentido, segundo proposto por Silverman (2009). Desse modo, para possibilitar a visualização e a compreensão dos dados de forma mais consistente, organizaram-se as informações de um grupo de elementos que compõem o conjunto dos diagnósticos e esses dados foram sistematizados em uma matriz de análise. No Quadro 2 consta um exemplo da comparação entre os diagnósticos realizados pelo professor 3 , antes e após o estudo.

Quadro 2 - Matriz de análise dos diagnósticos realizados pelo professor 3

\begin{tabular}{|c|c|c|c|c|}
\hline \multirow{2}{*}{$\begin{array}{c}\text { Subpapéis nos } \\
\text { esportes de } \\
\text { invasão }\end{array}$} & \multicolumn{2}{|c|}{$\begin{array}{c}\text { DIAGNÓSTICO REALIZADO } \\
\text { ANTES DO ESTUDO }\end{array}$} & \multicolumn{2}{|c|}{$\begin{array}{c}\text { DIAGNÓSTICO REALIZADO } \\
\text { APÓS O ESTUDO }\end{array}$} \\
\hline & $\begin{array}{l}\text { Dificuldades de } \\
\text { ordem tática }\end{array}$ & $\begin{array}{l}\text { Dificuldades de } \\
\text { ordem técnica }\end{array}$ & $\begin{array}{l}\text { Dificuldades de } \\
\text { ordem tática }\end{array}$ & $\begin{array}{l}\text { Dificuldades de } \\
\text { ordem técnica }\end{array}$ \\
\hline $\begin{array}{l}\text { Atacante com } \\
\text { posse de bola }\end{array}$ & & $\begin{array}{l}\text { - Passe muito forte } \\
\text { - Dificuldade em } \\
\text { receber a bola do } \\
\text { colega } \\
\text { - Deslocamentos } \\
\text { - Coordenação motora, } \\
\text { pé esquerdo e domínio } \\
\text { (dificuldades) } \\
\text { - Passe (dificuldades) } \\
\end{array}$ & $\begin{array}{l}\text { - Não observam } \\
\text { antes de agir } \\
\text { - Não passam para o } \\
\text { aluno desmarcado } \\
\text { - Não se direcionam } \\
\text { para o objetivo } \\
\text { - Não finalizam em } \\
\text { condições favoráveis }\end{array}$ & $\begin{array}{l}\text { - Não fazem o passe } \\
\text { corretamente } \\
\text { - Não se preocupam } \\
\text { com seu movimento } \\
\text { de drible } \\
\text { - Não conseguem } \\
\text { executar o } \\
\text { movimento de } \\
\text { deslocamento } \\
\end{array}$ \\
\hline $\begin{array}{l}\text { Atacante sem } \\
\text { posse de bola }\end{array}$ & & & $\begin{array}{l}\text { - Não ficam entre a } \\
\text { linha imaginária para } \\
\text { o passe [linha de } \\
\text { passe] }\end{array}$ & \\
\hline $\begin{array}{l}\text { Defensor do } \\
\text { atacante com } \\
\text { posse de bola }\end{array}$ & & & $\begin{array}{l}\text { - Não ficam entre o } \\
\text { marcador e o objetivo } \\
\text { - Não executam } \\
\text { a realização da } \\
\text { marcação correta } \\
\text { sobre o adversário } \\
\end{array}$ & $\begin{array}{l}\text { - Não executam } \\
\text { a realização da } \\
\text { marcação correta } \\
\text { sobre o adversário }\end{array}$ \\
\hline $\begin{array}{l}\text { Defensor do } \\
\text { atacante sem } \\
\text { posse de bola }\end{array}$ & $\begin{array}{l}\text { - Movimentação } \\
\text { (marcação) }\end{array}$ & & $\begin{array}{l}\text { - Não se preocupam } \\
\text { com seu marcador }\end{array}$ & \\
\hline
\end{tabular}

Fonte: os autores

Ao comparar os diagnósticos realizados pelo professor 3 é possível observar que das seis dificuldades identificadas no primeiro, cinco se referiam à execução de movimentos. 
No segundo, além de contemplar os quatro subpapéis dos esportes de invasão (atacante com posse de bola, atacante sem posse de bola, defensor do atacante com posse de bola e defensor do atacante sem posse de bola), o professor identificou 12 dificuldades, sendo a maioria delas vinculadas a importantes intenções táticas, relacionadas diretamente ao desempenho dos alunos nesse tipo de jogo. Na mesma linha, analisando os diagnósticos dos cinco participantes, percebeu-se que todos ampliaram suas possibilidades de leitura, passando a perceber dificuldades na atuação dos alunos que não notavam antes da participação no GE.

Também a comparação dos planejamentos das aulas realizados pelos professores no início e ao final do GE permite verificar diferenças consideráveis na compreensão dos procedimentos de ensino por parte dos participantes, no que se refere a: (a) seleção do objetivo da aula, (b) utilização de método de ensino, (c) escolhas das tarefas, (d) forma de intervenção privilegiada e (e) papel atribuído ao aluno durante a aula. Por exemplo, ao equiparar os planos de aula criados pelo professor 5 , percebe-se mudança tanto na forma de compreender o esporte, quanto na seleção do conteúdo. Essa transformação permitiu ao docente passar de uma aula constituída de um circuito com quatro tarefas sem tomada de decisão, seguido de um jogo formal (5v5 no futsal), para uma aula estruturada em um método de ensino, alinhado aos modelos de ensino para a compreensão (GONZÁLEZ; BRACHT, 2012; RAMOS; NASCIMENTO; GRAÇA, 2009) e com tarefas condizentes ao objetivo da aula (Quadro 3).

Quadro 3 - Comparação entre os planos de aula realizados pelo professor 5

\begin{tabular}{|c|c|}
\hline $\begin{array}{l}\text { PLANO DE AULA REALIZADO } \\
\text { ANTES DO ESTUDO }\end{array}$ & $\begin{array}{l}\text { PLANO DE AULA REALIZADO } \\
\text { APÓS O ESTUDO }\end{array}$ \\
\hline $\begin{array}{l}\text { Tema de ensino: futsal } \\
\text { Objetivo: } \\
\text { Desenvolvimento: } \\
\text { Aquecimento: tarefa tipo III ("bobinho"). } \\
\text { "Circuito", composto por quatro tarefas: } \\
\text { - tarefa tipo I (deslocamento conduzindo a } \\
\text { bola entre cones); } \\
\text { - tarefa tipo I (chute a gol); } \\
\text { - tarefa tipo I (passe e domínio da bola); } \\
\text { - tarefa tipo II (passe para um colega e } \\
\text { deslocamento em um espaço definido). } \\
\text { Jogo formal. }\end{array}$ & 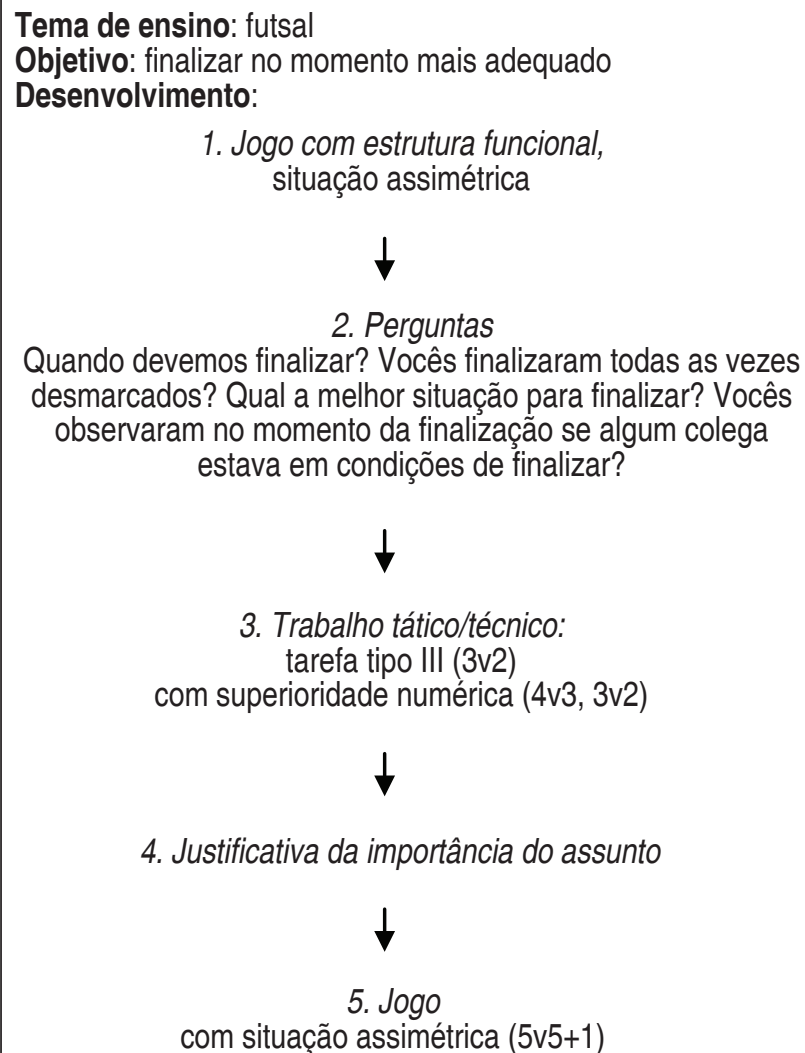 \\
\hline
\end{tabular}

Fonte: dos autores (2017) 
A forma de intervenção prevista pelo professor no plano realizado após o estudo também denota uma preocupação com a dimensão tática, ao prever que os discentes pensem no que estão fazendo, para atuar melhor. Aliado à intervenção, o tipo de tarefas selecionadas no primeiro plano condicionava o papel desempenhado pelos alunos - na maioria do tempo da aula - a meros reprodutores de movimentos. No segundo planejamento, diferente do primeiro, se propõe que os discentes tenham uma participação ativa durante o trabalho, necessitando refletir sobre o que estão fazendo todo o tempo da aula, o que potencializa a possibilidade de aprender a tomar decisões no jogo (GARGANTA, 2013; GRAÇA; MESQUITA, 2006).

A comparação das atuações dos professores nas aulas, registradas em vídeo antes e após do GE, também foi realizada com o uso da análise de conteúdo (SILVERMAN, 2009), baseada em quatro categorias: organização da aula, intervenção do professor, tipos de tarefas e papel do aluno. No Quadro 4, como exemplo, é apresentada a descrição sintética das observações das aulas filmadas no início e no final do GE em uma turma do professor 1.

Quadro 4 - Análise das filmagens das aulas do professor 1 com seus alunos

\begin{tabular}{|c|c|}
\hline AULA ANTES DO ESTUDO & AULA APÓS O ESTUDO \\
\hline $\begin{array}{l}\text { Organização da aula: a aula de futsal foi dividida } \\
\text { em dois momentos: execução de exercícios } \\
\text { em um aparelho denominado "escada de } \\
\text { coordenação" e o jogo formal. }\end{array}$ & $\begin{array}{l}\text { Organização da aula: pensada para o basquetebol, com a } \\
\text { quadra dividida em quatro partes, a aula apresentou cinco } \\
\text { fases: jogo com estrutura funcional, questionamentos, } \\
\text { trabalho técnico/tático, novos questionamentos e jogo formal. }\end{array}$ \\
\hline $\begin{array}{l}\text { Intervenção do professor. o docente demonstrou } \\
\text { corporalmente como realizar os movimentos na } \\
\text { escada de coordenação. Durante o jogo formal, } \\
\text { ele ficou parado, em pé, ao lado da quadra, } \\
\text { realizando a arbitragem do jogo e orientando } \\
\text { os alunos sobre: marcação, desmarcação e } \\
\text { execução do movimento correto ao finalizar. }\end{array}$ & $\begin{array}{l}\text { Intervenção do professor. durante as tarefas, o professor } \\
\text { se deslocou entre os jogos, orientando os alunos. Em } \\
\text { uma dessas intervenções, questionou: "Nessa situação, } \\
\text { quais as opções que você tem para passar a bola? } \\
\text { E quem está em melhores condições?". Em outra } \\
\text { intercessão, demonstrou a realização do pé-pivô como } \\
\text { um recurso para ajudar a encontrar um companheiro livre. }\end{array}$ \\
\hline $\begin{array}{l}\text { Tipos de tarefas: utilizando uma escada de } \\
\text { coordenação, o professor orientou quatro tarefas, } \\
\text { sendo todas tarefas orientadas a exercitar } \\
\text { habilidades técnicas de forma isolada. Após, os } \\
\text { alunos participaram do jogo formal. }\end{array}$ & $\begin{array}{l}\text { Tipos de tarefas: } \\
\text { - alongamento; } \\
\text { - jogo 3v3 em apenas uma tabela; } \\
\text { - jogo 3v3+1 em apenas uma tabela (duas equipes de } \\
\text { três jogadores se enfrentam, havendo outro participante } \\
\text { que será o curinga e atuará somente para o time que } \\
\text { estiver com a posse de bola. A equipe com a bola ataca e } \\
\text { a outra defende tentando adquirir o móvel para atacar); } \\
\text { - jogo formal (5v5). }\end{array}$ \\
\hline $\begin{array}{l}\text { Papel do aluno: a maior parte do tempo a atuação } \\
\text { dos alunos se limitou a reproduzir os movimentos } \\
\text { indicados pelo professor. Apenas no jogo formal } \\
\text { (realizado em uma quadra } 40 \mathrm{~m} \times 20 \mathrm{~m} \text { ) os alunos } \\
\text { tiveram oportunidade de tomar decisões na aula. }\end{array}$ & $\begin{array}{l}\text { Papel do aluno: participando de dois momentos de } \\
\text { reflexão sobre a importância de passar a bola ao } \\
\text { companheiro em melhores condições e de três tarefas } \\
\text { com interação entre adversários, o que demandou, em } \\
\text { consequência, tomar decisões. }\end{array}$ \\
\hline
\end{tabular}

Fonte: dos autores (2017)

Analisando as filmagens das aulas dos cinco professores com seus alunos, antes e após o estudo, foi possível observar que, em linhas gerais, no início os docentes utilizavam a estrutura clássica da abordagem tradicional do ensino dos esportes: alongamento e/ou aquecimento, proposição de tarefas em que os alunos não necessitavam tomar de decisões e o jogo formal.

Também antes do GE, as intervenções dos professores consistiam, basicamente, em orientar e corrigir falhas de ordem técnica, demonstrar como fazer os movimentos e realizar a 
arbitragem dos jogos. Fato comum foi perceber os docentes ao lado da quadra, em pé, com um apito, arbitrando a disputa dos alunos e marcando o tempo para realizar a troca das equipes que participavam do jogo formal.

Desse modo, durante essas aulas os alunos eram levados, na maior parte do tempo, a se ocuparem com a reprodução de movimentos, na medida em que não era necessário refletir sobre a ação. Escassas foram as tarefas propostas aos alunos em que eles precisavam decidir o que fazer.

Ao observar as filmagens das aulas após o estudo, interpretou-se que os cinco professores passaram a organizar suas aulas sob a ótica de um modelo de ensino centrado na tática. Dividindo a quadra em espaços que permitiam a realização simultânea de jogos reduzidos (três ou quatro ao mesmo tempo), os docentes desenvolveram as aulas observando quatro ou cinco momentos/partes, que incluíam realizar questionamentos aos alunos buscando que refletissem sobre a ação, propondo tarefas com interação entre adversários - característica dos JEC -, que oportunizam ao aluno o aprendizado do conteúdo selecionado para determinada aula.

Nessa linha, as intervenções dos professores passaram a focar na ideia de os alunos compreenderem o jogo, enfatizando a aprendizagem da tática. Os cinco docentes procuraram orientar e dialogar com os educandos, buscando que esses compreendessem o que e por que fazer, antes de como realizar uma determinada ação. 0 deslocamento dos professores pela quadra - circulando entre os jogos que ocorriam simultaneamente, parando a tarefa e orientando os alunos sobre a ação mais adequada -, aliado à demonstração corporal de como proceder, indicou uma compreensão diferente sobre o papel deles nas possibilidades de os alunos melhorarem seu desempenho (GONZÁLEZ; BRACHT, 2012). Interpreta-se que a percepção dos professores sobre o processo de aprendizagem dos discentes não era mais vista como algo natural, atrelado a uma ideia de talento, e sim como algo construído pelas oportunidades que os professores e as estratégias metodológicas podem oferecer.

Essa forma de intervenção, juntamente com a proposição de tarefas que exigem tomada de decisão, propiciou que os alunos assumissem um papel ativo durante as aulas (MESQUITA; GRAÇA, 2006). Nesse modo que os professores passaram a trabalhar, não basta a execução dos movimentos técnicos demandados pelo esporte, é preciso refletir e questionar sobre as razões de realizar cada ação.

Ao analisar o processo de mudança nas atuações dos professores, descrito em seu conjunto, ficou bastante evidente a importância da realização de cinco reuniões de estudos, em que um dos pesquisadores desempenhou o papel de docente e os participantes do GE assumiram a função de alunos. Nesses encontros, ocorreu o que poderia ser chamado de materialização do conhecimento procedimental, uma vez que os professores observaram como realizar, na prática, todo o aporte teórico que o grupo havia estudado.

\section{CONSIDERAÇÕES FINAIS}

É difícil os professores mudarem a maneira de conceber e conduzir o ensino dos esportes. Diversos são os entraves que limitam e dificultam essa possibilidade. No entanto, apesar de o caminho ser longo e árduo, os resultados desta pesquisa permitem defender a convicção de que as mudanças são possíveis. 
Conclui-se que os professores forjam, ao longo de suas vidas, concepções que naturalizam o ensino do esporte numa perspectiva tradicional (o desempenho do aluno depende de uma capacidade inata/natural; 0 desinteresse dos sujeitos não permite 0 aprendizado; a impossibilidade de jogar sem o pleno domínio da execução dos movimentos). Essas concepções mostraram-se como entraves que dificultam, pelo menos inicialmente, 0 estranhamento e mudanças na forma de atuação docente.

Para os professores participantes, a mudança da concepção de ensino iniciou a partir do momento que o conjunto de temas propostos nas reuniões foi abordado de forma articulada. No entanto, essa transformação não foi o bastante para que os docentes pudessem alterar a forma de planejar e conduzir suas aulas. Foi necessário realizar experiência de ensino na quadra junto com os professores para que as mudanças começassem a se efetivar na forma de conceber e realizar o trabalho. Durante esses encontros, cada integrante do grupo planejou e ministrou uma aula prática, refletindo criticamente tanto sobre a sua atuação como a respeito do desempenho dos outros integrantes do grupo. De acordo com Tardif (2002) ensinar supõe aprender a ensinar, para o ensino dos esportes e práticas corporais de forma geral, essa condição também se aplica.

Nesse sentido, é importante que os professores dominem os fundamentos teóricos que sustentam a forma de ensino dos esportes centrada na tática. Defende-se, com isso, que não é possível deixar de ensinar os JEC na perspectiva do modelo tradicional sem um subsídio teórico adequado, que possibilite a compreensão dessa dimensão na regulação das ações de jogo. Do mesmo modo, é importante que os educadores, após estudar formas e propostas metodológicas existentes no meio acadêmico, criem, proponham, testem instrumentos para utilização em suas aulas, em vez de apenas aplicar proposições de ensino pensadas por outros.

Nesse processo, a pesquisa-ação - enquanto ferramenta de investigação - permitiu a um dos pesquisadores atuar como mediador na tentativa de auxiliar os professores a refletirem e repensarem seu cotidiano profissional, oferecendo-lhes condições para mudar a prática docente. Dessa forma, foi possível confirmar que a pesquisa-ação é um excelente instrumento para auxiliar na mudança da concepção de ensino acerca dos esportes. Nesse contexto, a atuação do pesquisador tem grande relevância no processo e constitui-se como um aspecto importante a ser considerado em pesquisas com características similares.

As consequências da experiência de formação colaborativa analisada nas concepções e nas formas de professores de EF ensinar JEC apontam que o processo de mudança é possível. Os docentes que atuam orientados por um modelo tradicional de ensino podem transformar suas possibilidades de compreender o fenômeno esportivo e ensinar os alunos a jogar bem e melhor. No entanto, o empreendimento é longo, trabalhoso e precisa ser ancorado em fundamentos teóricos relacionados à dimensão tática, com pesquisadores conhecedores do processo, munidos de saberes e argumentos consistentes.

Particularmente, a formação universitária - por ser um elemento crucial na constituição de concepções de ensino - precisa discutir a ocorrência de formação de professores na perspectiva tradicional de conceber os JEC, como ainda se identifica em muitas instituições no Brasil (COUTINHO; SILVA, 2009).

Além disso, são necessários mais estudos. De preferência, pesquisas que ofereçam aos professores a oportunidade de formação permanente de longo prazo, por meio de estudos 
colaborativos, sem que os participantes precisem sair do seu ambiente de trabalho, como foi o caso desta investigação. Assim, talvez se consiga amenizar as dificuldades que os professores têm de manter em seu cotidiano uma rotina de estudo contínuo.

\section{REFERÊNCIAS}

BAYER, Claude. 0 ensino dos desportos coletivos. Lisboa: Dinalivro, 1994.

CARMEL, Erran; AGARWAL, Rajshee. Tactical Approaches for Alleviating Distance in Global, IEEE Software, v. 1, n. 2, p. 22-29, 2001.

CÔTÉ, Jean; HANCOCK, David. Evidence-based policies for youth sports programs.

International Journal of Sport Policy and Politics, v.8, n.1, p.51-65,2014.

COUTINHO, Nilton F.; SILVA, Sheila A. Conhecimento e aplicação de métodos de ensino para os jogos esportivos coletivos na formação profissional em educação física. Movimento, v. 15, n. 1, p. 117-144, jan./mar. 2009.

FRANCO, Maria A. S. Pedagogia da pesquisa-ação. Educação e pesquisa, v. 31, n. 3, p. 483502, set./dez. 2005.

GARGANTA, Júlio M. A propósito do desenvolvimento, da identificação e da atualização do talento para treinar e jogar futebol. In: NASCIMENTO, Juarez V.; RAMOS, Valmor; TAVARES, Fernando (Org.). Jogos desportivos: formação e investigação. Florianópolis: UDESC, 2013. v. 4, p. 463-484.

GONZÁLEZ, Fernando J.; BRACHT, Valter. Metodologia do ensino dos esportes coletivos. Vitória: UFES, Núcleo de Educação Aberta e a Distância, 2012.

GONZÁLEZ, Fernando J.; FRAGA, Alex B. Referencial Curricular de Educação Física. In: RIO GRANDE DO SUL. Secretaria de Estado da Educação. Departamento Pedagógico.

Referenciais Curriculares do Estado do Rio Grande do Sul: Linguagens, Códigos e suas Tecnologias. Porto Alegre: SE/DP, 2009. v. 2, p. 113-181.

GRAÇA, Amândio. Os contextos sociais do ensino e aprendizagem dos jogos desportivos coletivos. In: NASCIMENTO, Juarez Vieira do; RAMOS, Valmor; TAVARES, Fernando (Org.). Jogos desportivos: formação e investigação. Florianópolis: UDESC, 2013. v. 4, p. 79-102.

GRAÇA, Amândio; MESQUITA, Isabel M. R. Modelos de ensino dos jogos desportivos. In: TANI, G.; BENTO, J. O.; PETERSEN, R. D. S. (Org.). Pedagogia do desporto. Rio de Janeiro: Guanabara Koogan, 2006. p. 269-283.

GREENWOOD, Davyd; LEVIN, Morten. Reconstruindo as relações entre as universidades e a sociedade por meio da pesquisa-ação. In: DENZIN, N. K.; LINCOLN, Y. S. (Org.). 0 planejamento da pesquisa qualitativa: teorias e abordagens. Porto Alegre: Artmed, 2006. p. 91-113.

GRIFFIN, Linda; MITCHELL, Stephen A.; OSLIN, Judith L. Teaching Sport Concepts and Skills: a tactical games approach. Champaign: Human Kinetics, 1997. 
KIRK, David; MACPHAIL, Ann. Teaching games for understanding and situated learning: rethinking the Bunker-Thorpe model. Journal of Teaching in Physical Education, v. 2, n. 21, p. 177-192, 2002.

LIGHT, Richard; TAN, Steven. Culture, embodied experience and teachers' development of TGfU in Australia and Singapore. European Physical Education Review, v. 12, n. 1, p. 99-117, 2006.

MESQUITA, Isabel M. R. Perspectiva construtivista da aprendizagem no ensino do jogo. In: NASCIMENTO, Juarez V.; RAMOS, Valmor; TAVARES, Fernando (Org.). Jogos desportivos: formação e investigação. Florianópolis: UDESC, 2013. v. 4, p. 103-131.

MESQUITA, Isabel M. R.; GRAÇA, Amândio. Modelos e conceções de ensino dos jogos desportivos. In: TAVARES, Fernando (Org.). Jogos desportivos coletivos: ensinar a jogar. Portugal: FADEUP, 2013. p. 9-54.

PEARSON, Philip J.; WEBB, Paul. Developing effective questioning in teaching games for understanding (TGfU): a paper presented at the 1st Asia Pacific in Education Conference, Adelaide, 2008. Disponível em: < http://ro.uow.edu.au/cgi/viewcontent. cgi?article=1054\&context=edupapers $>$. Acesso em: 8 fev.2017.

RAMOS, Valmor; GRAÇA, Amândio B. S.; NASCIMENTO, Juarez V. A representação do ensino do basquetebol em contexto escolar: estudos de casos na formação inicial em educação física. Revista Brasileira de Educação Física e Esporte, v. 20, n. 1, p. 37-49, jan./mar.2006.

RAMOS, Valmor; NASCIMENTO, Juarez V.; GRAÇA, Amândio. Análise do processo de instrução no treino de jovens: um estudo de caso no basquetebol. Revista Portuguesa em Ciências do Desporte, v. 9, n. 1, p. 52-63, jan. 2009.

SIEDENTOP, Daryl. Sport Education: a retrospective. Journal of Teaching in Physical Education, v. 21, p. 409-418, 2002.

SILVERMAN, David. Interpretação de dados qualitativos: métodos para análise de entrevistas, textos e interações. Porto Alegre: Artmed, 2009.

TARDIF, Maurice. Saberes docentes e formação profissional. Petrópolis, RJ: Vozes, 2002.

TAVARES, Fernando. Jogos desportivos coletivos: contributos para a sua análise e funcionamento. In: RAMOS, Valmor; SAAD, Michel A.; MILISTETD, Michel (Org.). Jogos desportivos: investigação e prática pedagógica. Florianópolis: UDESC, 2013. v. 3, p. 17-51.

THIOLLENT, Michel. Metodologia da pesquisa-ação. São Paulo: Cortez, 2011.

TRIPP, David. Pesquisa-ação: uma introdução metodológica. Educação e Pesquisa,v. 31, n. 3 , p. 443-466, set./dez. 2005. 
